\title{
Cortical self-regulation in patients with epilepsies
}

\author{
Brigitte Rockstroh ${ }^{\mathrm{a}}$, Thomas Elbert ${ }^{\mathrm{b}}$, Niels Birbaumer ${ }^{\mathrm{c}, \mathrm{e}}$, Peter Wolf ${ }^{\mathrm{d}}$, Andreas Düchting- \\ Röth $^{\mathrm{d}}$, Martin Reker ${ }^{\mathrm{d}}$, Irene Daum ${ }^{\mathrm{e}}$, Werner Lutzenberger ${ }^{\mathrm{e}}$ and Johannes Dichgans ${ }^{\mathrm{e}}$ \\ ${ }^{a}$ Department of Psychology, University of Konstanz, Germany, ${ }^{b}$ Institute for Experimental Audiology, University of Münster, Germany, \\ 'Universitá degli Studi, Padua, Italy, 'Epilepsy Center Bethel. Bielefeld, Germany and Department of Clinical and Physiological \\ Psychology and Department of Veurology, University of Tïbingen. Germany
}

Key words: Self-regulation; Biofeedback: Slow cortical potentials; DC potentials; (Epilepsy)

\begin{abstract}
The present study aimed at investigating to what extent the regulation of excitability in cortical networks, as indicated by surfacenegative slow cortical potentials (SCPs), is impaired in epileptic patients and to what extent training of SCP self-regulation by means of biofeedback and instrumental learning procedures might affect seizure frequency. Twenty-five patients suffering from drug-refractury epilepsies (complex focal. grand mal, and absence type of seizures) participated in 281 -h sessions of feedback and instrumental conditioning of their SCPs. Subjects EEGs were obtained from the vertex. Depending on discriminative stimuli DC shifts towards increased or suppressed negativity relative to the pre-trial baseline were demonstrated by on-line visual feedback during intervals of $8 \mathrm{~s}$ each; each session comprised 110 trials. While performance on the SCP self-regulation task was initially below normal (as compared to healthy subjects), significant increases in SCP control were achieved by the patients across the 28 training sessions. In IS patients at least 1-year follow-up data are available. Changes in seizure frequency were related to transfer of SCP control with six of the patients becoming seizure-free. Age affected the ability to acquire SCP control and its impact on seizure frequency.
\end{abstract}

\section{Introduction}

The development of antiepileptic drugs (AEDs) has generated dramatic changes in the treatment and rehabilitation of patients suffering from epilepsies. However, it remains a pertinent problem that, dependent on the type of epilepsy. $20-50 \%$ of patients are not controlled with antiepileptic medication alone. Alternative approaches relying on behavioral treatment alone or in combination with pharmacological treatment have therefore been explored. This research was stimulated by a famous single case study published by Efron'? doc-

Currespondence to: Prof. Dr. Brigitte Rockstroh. Department of Psychology. P.O. Box 5560 . D-7750 Konstanz. Germany. Tel.: $07531-882085$. umenting the classical conditioning of aura disruption. During the last two decades. seizure control and reduction in seizure frequency have been reported following the application of desensitization and extinçtion procedures ${ }^{21-23.45}$, self-control procedures implying self-perception, self-control and relaxation ${ }^{+9.910}$, biofeedback of respiratory parameters ${ }^{24}$, and instrumental modification of EEG spectra, ${ }^{25,+3}$ (for recent overviews see Birbaumer et al. ${ }^{1}$ and Elbert et al. ${ }^{20}$ ).

The approach described in the present paper relies on biofeedback and instrumental conditioning of surface-negative slow cortical potentials ( $\mathrm{SCP}$ ). SCPs represent the extent to which apical dendrites of the cortical pyramidal cells are depolarized and hence indicate neuronal excitability ${ }^{1+18 .+10 .+1}$. A 
typical representative of SCPS is 'contingent negative variation' (CNV), which can be recorded from the scalp during the interstimulus interval, while the subject is anticipating the second event and preparing for task performance, i.e., dependent on a stimulus contingency (review: $\mathrm{McC}$ allum ${ }^{27}$ ). Thus, those brain regions which are expected to become involved in the contingency processing or performance preparation will be pre-activated by the cue stimuli, which is indicated by a phasic change in cortical excitability. The electrical potential originates primarily in the cerebral cortex, when excitatory thalamic input depolarizes the apical dendrites over extensive cortical regions ${ }^{28.33 .39}$ (for review of evidence see also Birbaumer et al. ${ }^{1}$ and Rockstroh et al. ${ }^{35}$ ). While there is evidence that excitability is regulated according to the constantly varying environmental and metabolic demands, it must also be assumed that feedback mechanisms within the brain carefully control the range of this excitability. Overexcitability of cortical tissue, as might be initiated by a transient failure in down-regulating mechanisms, would allow an explosive chain reaction of excitation among neuronal network ${ }^{3.18}$. Given that changes in SCP reflect changes in cortical excitability, extreme negative shifts that result from overexcitability of cortical neuronal networks should indicate a high risk for seizures to develop. That there is a connection between surface-negative SCPs and increased excitability of underlying cortical neuronal tissue is supported by the development of pronounced negative DC shifts under hyperventilation - a procedure known to increase excitability in neuronal tissue due to metabolic changes ${ }^{5.31}$. Furthermore, anticonvulsants significantly reduce surface negativity in healthy subjects ${ }^{36.38}$. Evidence from animal experiments as well as observations from human subjects suggest a link between abnormal negative SCPs and epileptic activity. In the cat the negative shift with onset of seizure activity in the EEG (induced by epileptic agents such as pentylenetetrazol or penicillin) coincides with paroxysmal depolarization shifts (PDS) in cortical neurons ${ }^{6.7}$. Furthermore, widespread negativity appears during generalized tonic-clonic seizure activity and is followed by positive-going repolarization with termination of the seizure ${ }^{+\downarrow}$. Patients who undergo an epileptic attack during hyperventilation tend to exhibit extreme potential shifts exceeding $100 \mu \mathrm{V}$. This supports the hypothesis that abnormal increases in excitability covary with a risk for seizures to develop ${ }^{5.3}$. This evidence suggests that slow negative potential shifts can be considered a sign of cortical excitability, and that excitability which increases beyond control favors an epileptic attack. We might assume that epileptic patients are vulnerable to cortical excitement that is beyond their control, or, in other words, from an impaired or at least transiently failing regulation of their cortical excitability. Such a deficit should be manifest in an impaired capacity for self-regulation of slow cortical potentials ${ }^{32}$.

In the $\mathrm{SCP}$ self-regulation paradigm ${ }^{14-16}$ subjects receive on-line feedback of their surface-recorded SCPs and are reinforced for increasing or reducing their SCPs above or below a pre-stimulus baseline level depending upon discriminative stimuli. Numerous studies from different laboratories have demonstrated that healthy human subjects can achieve 'control' over their SCPs in this paradigm - i.e., they produce significant differences between required negativity increase and negativity suppression - within 100-200 training trials (or two training sessions) without mediating of artificial influence from other physiological systems ${ }^{30,34.35 .37}$. Two preliminary studies with epileptic patients revealed a reduced capacity for selfregulation compared to healthy subjects - i.e., only one out of a total of 18 patients demonstrated SCP differentiation within two feedback sessions 2.20 . While this evidence should support our hypothesis that epileptic patients suffer from impaired control over their cortical excitability (SCPs), it is also of interest whether and to what extent SCP regulation could be improved if feedback and instrumental conditioning are extended to many training sessions. If regulation and control over cortical excitability were, represented in the regulation and control over surface-recorded SCPS and if acquisition of SCP control were related to a stabilization of an impaired excitability regulation in epileptic patients, then patients might profit from an extended training with respect to seizure frequency.

As a test for this hypothesis, 14 patients suffering from drug-refractory epilepsy (complex focal, 
grand mal and absence type of seizures) participated in a training period that was extended to $281-\mathrm{h}$ sessions. Within a double-blind setting seven patients received feedback of their vertex-recorded SCPs and were reinforced for systematically increasing or suppressing surface negativity relative to the pre-trial baseline level, while seven patients received feedback of the activity in the alpha frequency range $(9-15 \mathrm{~Hz})$ and were reinforced for increasing or reducing the activity in the alpha band depending upon the discriminative stimuli. The latter group served to control for the specificity of excitability control by means of SCPs. The results ${ }^{19.20}$ indicated that four of the seven patients demonstrated SCP control at the end of the training period. Only the group receiving SCP feedback demonstrated a significant reduction in seizure frequency from pre-training. From these results we concluded that nonspecific 'placebo' effects of the biofeedback procedure were unlikely to affect seizure frequency.

The main goal of the present study was to expand the investigation of the acquisition of control over SCPS to a large group of drug-refractory patients. Given the evidence that feedback of alpha activity did not affect seizure frequency in the preceding study cited above and given ethical considerations, we decided not to investigate a (placebo) control group any further. In addition to the acquisition of SCP control and its relationship to a change in seizure frequency, possible determinants (such as age, medication, type of epilepsy, pretraining seizure frequency) of acquisition and learning progress were evaluated.

\section{Methods}

\section{Subjects}

Twenty-five patients (13 females, 12 males) participated in a standardized training program (see below). The mean age of the patients group was $30.1 \pm 1.8$ years (range $15-49$ years). Patients suffered from complex focal seizures $(N=20)$, secondary generalized grand mal $(N=1)$, petit mal epilepsy or absences $(N=4)$. Patients" seizure history ranged from 3 to 15 years. A minimum of one seizure per week was required for patients to be included in the sample. The average seizure fre- quency varied from 1 /week to more than 60 /week (series of absences) around a mean of 11.5 (calculated from individual medians during baseline). Individuals with progressive neurological conditions, pseudo- or nonepileptic seizures, or psychiatric complications were not included in the sample, nor were patients suffering primarily from attacks during sleep.

Fifteen patients were trained at the Tübingen University, 10 patients at the Epilepsy Center in Bethel, Bielefeld. (Training procedure, data acquisition, and data analyses were the same at both places.)

Patients were under constant neurological supervision by the Department of Neurology, University of Tübingen, or the Epilepsy Center Bethel. Standard EEG diagnostics were carried out prior to and following the training period. Medication regimens remained constant throughout the baseline. training, and follow-up periods, anticonvulsant blood levels being checked at regular intervals. Medication regimes were highly variable ranging from monotherapy to regimens with various types of antiepileptics.

\section{Design and procedure}

Within each training session continuous visual feedback from the vertex $(\mathrm{Cz})$ SCP was provided to the subject during intervals of $8 \mathrm{~s}$ each by means of the outline of a rocket ship appearing on a TV screen in front of the subject (see Fig. 1). The position of the rocket ship at any time $t$ during the feedback interval was a function of the actual DC shift. The EEG was filtered on-line to 0.5 -s points in order to reduce spontaneous oscillations and to correct for artifacts. These values were referred to a prestimulus baseline of $4 \mathrm{~s}$ preceding the onset of the feedback and signal stimuli. The value of the rocket's position was basically the integrated EEG during the feedback interval (see also Rockstroh et al. ${ }^{37}$ for details of the algorithm). Depending upon visual discriminative stimuli (the letters ' $A$ ' or ' $\mathrm{B}$ ' presented on the TV screen simultaneously with the feedback stimulus) the subject was asked to modulate the SCP response in either a negative or a positive direction. Forward movements of the rocket ship signalled the required SCP shift. while backward movements indicated inadequate perfor- 


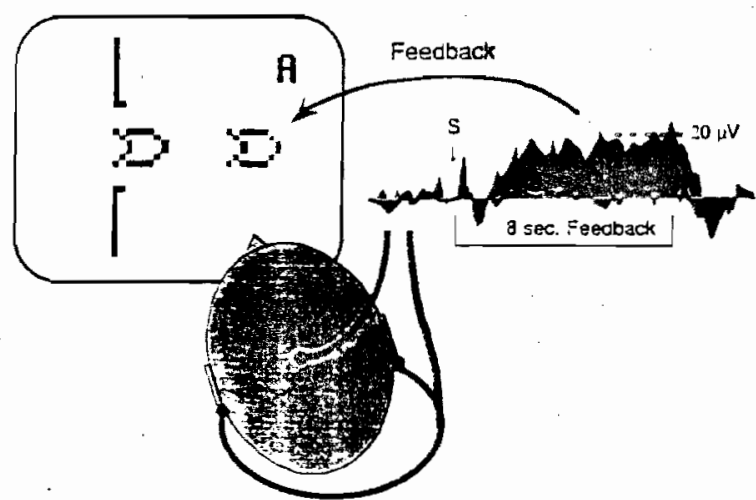

Fig. 1. Schematic illustration of the feedback mode. The curves on the right represent examples of the filtered on-line raw EEG from the vertex etectrode (referred to linked earlobes) prior to and during the feedback interval. The upper curve (gray area) indicates a DC shift towards increased negativity relative to the baseline interval (the beginning of the feedback interval is indicated by ' $S$ '), the lower curve (black area) represents a $D C$ shift when negativity is suppressed. The letter ' $A$ ' in the upper right comer of the schematically illustrated TV screen in front of the subject signals that in this example of a particular trial, a shift towards increased negativity is required in order to move the feedback stimulus (outline of rocket ship) from its starting position between the two vertical bars towards the right. The relationship between the negative shift and the feedback is marked by the arrow.

mance. Thus, the letter ' $A$ ' signalled that an increase in negativity above the mean of the pre-trial baseline would move the rocket ship forward, while the letter 'B' asked for negativity suppression. On-line artifact control procedures prevented movements of the signal from being affected by eye movements, muscular artifacts or tiny electrode displacements. The effect of conditioning or 'transfer of learning' was tested on transfer trials in which only the signal stimuli (e.g., 'A' or 'B') were presented and no feedback was provided. Each patient completed 28 sessions. Within each session an initial block of 20 transfer trials was followed by two blocks of 30 feedback trials each, while the session terminated with another 30 transfer trials. Within each trial block ' $A$ ' and 'B' trials alternated pseudorandomly.

The first block of 20 training sessions was preceded by a baseline period of 8 weeks. during which frequency and type of seizures were monitored by the patients, and during which neurological and neuropsychological assessments took place. The training sessions were held for 2 weeks (two 1 -h sessions per day with a 2-day break separating each training week). Following an intermission of 8 weeks, designed as a first 'transfer', patients underwent another eight sessions of training (the 'booster' sessions). Sessions 10 through 28 included playing a radio program chosen by the subject in order to approach distracting conditions of real life: patients should ideally be able to regulate the brain's activity not only when they concentrate fully on the self-regulation task but also during everyday activities and circumstances. Patients were encouraged to practise the acquired SCP during the intermission by realizing their strategies for SCP control on ' $A$ ' and ' $B$ ' trials five times per day for about $5 \mathrm{~min}$ each. Throughout the year following the 'booster' training, patients continued this home practice, which was verified by daily ratings and regular contacts with the attending staff member. Throughout the entire time period (from the beginning of baseline until the end of follow-up) patients kept diaries specifying seizure frequency, and completed a questionnaire on symptoms, antecedents and consequences for every seizure.

Neuropsychological testing was scheduled prior to the first and following the second training period as well as after the 12-month follow-up period. The test battery comprised tests of verbal and spatial inteliigence and short- and long-term memory, a test of leit-right orientation, and a test associated with frontal lobe function. Results are reported elsewhere"

\section{Physiological recordings}

The EEG was recorded from $\mathrm{Cz}$ using a Beckman type 511 polygraph in the Tübingen laboratory and a Schwarzer-Picker ES 10.000 electroencephalograph in Bethel with a time constant modified to $30 \mathrm{~s}$ for SCP recording. The middle of a fixed $10-k \Omega$ shunt attached berween electrodes at both earlobes was used for reference. Nonpolarizable $\mathrm{Ag} / \mathrm{AgCl}$ electrodes (ZAK) were used for EEG recording: earlobe electrodes (Schwarzer) were affixed with clips. Grass paste EC2 served as the electrolyte. Vertical eye movements were monitored via nonpolarizable $\mathrm{Ag} / \mathrm{AgCl}$ electrodes (Beckman) that were tilled with Beckman (Synapse) electrode jelly as a conducting agent. These electrodes were placed $1 \mathrm{~cm}$ above and below the 
left eye. Each electrode site was cleansed with alcohol, and the scalp electrode site was furthermore abraded with a sterile lancet to reduce electrode resistance below $5 \mathrm{k} \Omega$. Data were sampled at a rate of $100 \mathrm{~Hz}$.

\section{Apparatus}

DEC PDP 11/73 computers were utilized to acquire and store the physiological data. to detect artifacts and to compute the feedback values online. These values were passed via a serial line to a Commodore Amiga computer which served to generate the visual feedback. Off-line analysis was done on Macintosh computers making use of the statistical packages StatView and SuperAnova.

\section{Data analysis}

(1) Acquisition of control over SCP activity. The area below the curves for the entire 8-s interval referred to baseline served as score to evaluate SCPs. This score was averaged across artifact-free trials for the different trial types ('A' and ' $B$ ' trials, negativity increase and negativity suppression); the difference in SCPs between 'A' and 'B' trials was then averaged across subjects and trials of the different trial blocks (first and second period of feedback trials, first and second period of transfer trials). For each patient the mean differentiation in SCPs between the two trial types averaged across all 28 sessions was evaluated by $t$-tests, again separately for the four trial blocks; $t$-values were transformed to $z$-values which were agglutinated over subjects for the evaluation of group effects (z(group) $=z(N)$. The concomitant $95 \%$ confidence limits were computed according to the equation: $z_{\text {(group) }} \pm 1.96 \times \mathrm{SD}_{\mathrm{z}}$. (In order to evaluate differences between the two laboratories, this analysis was accomplished for the entire sample as well as for the two groups. Since no signiticant differences between the two groups were found, results will be reported for the entire sample.) Furthermore, the change in SCP differentiation across the 28 training sessions was evaluated by polynomial regression, again for each patient and for the group of patients.

\section{2) Seizure frequency. For every patient the me-}

dian seizure frequency was calculated for the baseline period ( 8 weeks) and for the 1-year follow-up period (beginning with the end of the 28 training sessions). The ratio of seizure frequency during follow-up relative to seizure frequency during baseline was then plotted against and correlated with the $t$-values of SCP differentiation as well as the change in SCP differentiation ( $y$-value of the regression analysis). In order to evaluate factors that might have caused a change in seizure frequency, the group was divided into subjects who became completely seizure-free, those with reductions and subjects with little or no change in symptomatology. Then ANOVAs with this between subject factor were computed (a) for the SCP differentiation achieved under feedback, (b) the amount of transfer, computed as the fraction transfer differentiation divided by feedback differentiation, and (c) the patient variables age, diagnosis and seizure frequency during baseline.

Additionally, the possible impact of age, medication ${ }^{*}$, and diagnosis on learning criteria ( $t$ values and regression coefficients for the four different trial blocks) as well as on the change in seizure frequency was examined by simple and multiple regressions.

\section{Results}

\section{Acquisition of control over $S C P$}

Fig. 2 illustrates a typical example of SCPs during transfer trials. Only little and often no systematic differentiation in SCP was achieved during the first few sessions, but a marked increase in SCP differentiation was demonstrated towards the end of the training period. While (averaged across all 25 patients, Fig. 3) the mean differentiation between ' $A$ ' and ' $B$ ' triais, i.e., between required negativity increase and negativity suppression, under feedback conditions was close to zero $(-1.9 \mu \mathrm{V})$

\footnotetext{
* As it turned out that the majority of patients were on drug regimes comprising two or more AEDs, analyzing the effects of medication by means of plasma levets seemed impossible. In order to obtain a first impression on possible drug effects, the amount of daily drug intake was taken as score for regression analyses. We are aware that this is not appropriate, so that the effects of AEDs on learning and its impact on seizure frequency should be evaluated more specifically in luture studies.
} 
uransfer 1 Tansfer 2
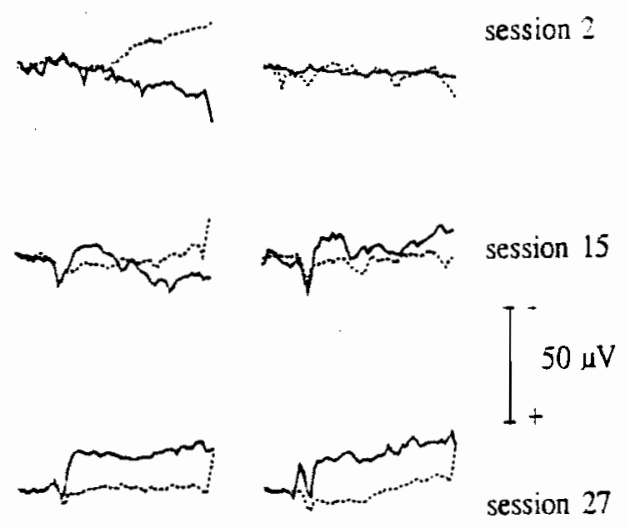

Fig. 2. Example of averaged slow waves during transfer trials from an arbitrarily selected parient. Solid lines: required negativity; dotted lines: required positivity.

during the first session, it increased to $+13.2 \mu \mathrm{V}$ on the 28th session: the mean values for the second transter period at the end of each session were $2.7 \mu \mathrm{V}$ on the first and $4.6 \mu \mathrm{V}$ on the last session.

For the patient group SCP differentiation across the 28 sessions was significant under all conditions (for the first feedback block: $z=5.2 . P<0.01$, the second feedback block: $z=6.8, P<0.01$. the first and the second transfer blocks: $z=2.3$ and 2.2.

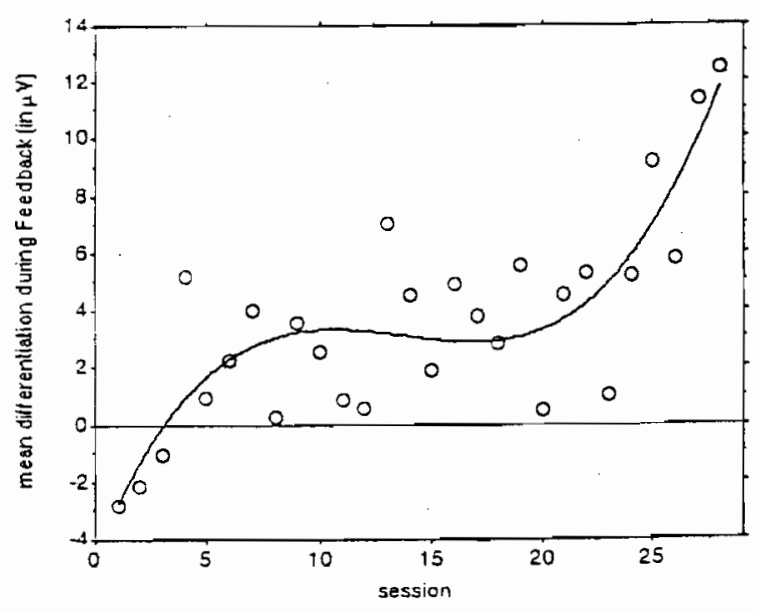

Fig. 3. Vean differentiation in SCPS (in $\mu \mathrm{V}$, ordinate) as achieved by the patient group $(\mathrm{N}=25)$ during each of the 28 training sessions (abscissa) under feedback conditions (mean of. first and second feedback block in each session). Each circle represents the group mean of one session. Note the significant simpie and cubic trend indicating the progress of SCP differentiation across sessions and mainly during sessions 21-28. respectively, $P<0.05$ ). Seventeen of the 25 patients achieved significant SCP differentiation under at least one condition (feedback or transfer), nine of them demonstrated significant transfer).

Fig. 3 illustrates the increase in SCP differentiation under feedback conditions across sessions, which turned out to be most pronounced during the second training period from session $2 \mathrm{~L}$ to 23 . This is confirmed by a significant cubic trend for all feedback trials taken together $(F(3,24)=17.3, P$ $<0.001 ; t(27)=3.4$ for the simple, $t(27)=3.3$ for the quadratic, and $t(27)=3.5$ for the cubic trend, $P<0.01)$. For the second transfer block a significant simple regression was obtained $(F(1,26)=$ $19.9, t=4.5, P<0.01$ ), indicating an average increase in training success of $0.33 \mu \mathrm{V} /$ session.

\section{Change in seizure frequency}

Seven patients stopped monitoring seizure frequency during the 1-year follow-up period. Accordingly, the change in seizure frequency and its relationship to SCP control was analyzed for 18 subjects. Compared to baseline levels, seizure incidence was significantly lower during the follow-up period $(F(1,17)=21.7, P<0.01)$. Of the $18 \mathrm{pa}-$ tients six have become completely seizure-free (outcome group 1). Another seven patients showed reductions of seizure incidence compared to baseline (outcome group 2). The remaining five patients did not exhibit changes in seizure frequency (outcome group 3). The frequency distribution of the change in seizure frequency demonstrates these three groups (Fig. 4).

While the success in SCP differentiation was about in the same range in all three outcome groups, the rate of transfer (defined as transfer

\footnotetext{
* Four months after the end of the training period. generalization of SCP control and correceness of home practice were evaluated in a session in which patients were asked to produce ' $A$ ' and ' $B$ ' states as they do at home. while the EEG was monitored. This testing was realized in an office in which the patient had nor been before, in order to avoid possible effects of conditioning to experimental context. However. this examination could not be obtained for every patient: therefore. results are not reported. Of the nine patients who were examined for generalization of SCP control 4 months after completion of the training. hive patients could still produce a systematic change in their EEG potential, when asked to produce the ' $A$ ' or the ' $B$ ' response.
} 
differentiation divided by feedback differentiation) was significantly different $(F(2,15)=4.5, \quad P$ $<0.05$ ): compared to patients who did not experience a change in seizure frequency or to those demonstrating seizure reduction, the transfer rate was 5-20 times higher in patients who became seizurefree.

Neither diagnosis nor the amount of medication turned out to be significantly different for these three groups. The number of seizures during the baseline interval was highest for outcome group 2 (with moderate reduction of seizures; $25.1 \pm 11.5$ ) compared to $3.7 \pm 2.0$ for outcome group 1 (seizure-free) and $1.6 \pm 0.4$ in patients with unchanged symptomatology $(F(2.15)=2.9, P<0.1)$. (The effect for outcome group 2 may be due to the patients with very many absences in this group, although it should be kept in mind that the change in seizure frequency was estimated as the ratio of seizures during follow-up relative to baseline.) $\mathrm{Pa}$ tients becoming seizure-free were younger than members of the other two groups $(22 \pm 3$ years vs. $36 \pm 3$ years and $35 \pm 5$ years, respectively; $F(2.15)=5.0, P<0.02)$.

Additionally, a stepwise multiple regression was performed to explain the variance in this measure; dependent variables were the criteria for SCP con-

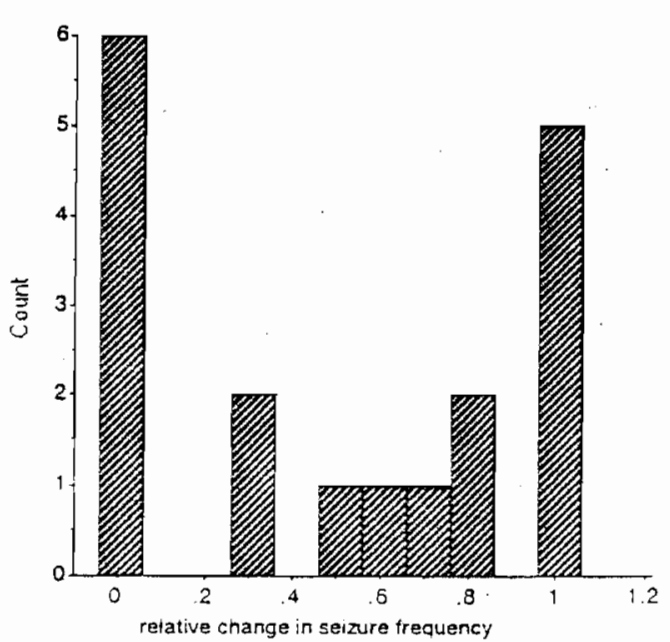

Fig. 4. Frequency distribution of the relative changes in seizure frequency, computed as the fraction of median seizure incidence during the follow-up divided by the mediun during a 3-month baseline. A value of 0 on the abscissa means that a patient has become seizure-free during the lollow-up period, a value of 1 means that seizure incidence has remained unchanged. trol, age, diagnosis, amount of medication, and baseline seizure frequency. The resulting significant multiple correlation of $R=0.82(F(3,14)=$ 9.6, $P=0.01$ ) indicates that $65 \%$ of the variance in seizure reduction can be explained by the SCP differentiation during the second feedback block $(t=$ 4.0, $P<0.01$ ), SCP differentiation during the second transfer block $(t=2.7, P<0.05)$ and age $(t=$ $3.2, P<0.05$ ). This points to the ability to transfer' SCP control being the relevant variable for a reduction in seizure frequency, and that such a transfer is much better achieved by younger patients.

\section{Discussion}

The present results confirm and strengthen those of the preceding study $y^{20}$ indicating that the majority of drug-refractory patients can achieve control over their SCPs after extended training involving feedback and instrumental conditioning. The larger sample size of the present study allowed us to consider possible predictors of beneficial changes in seizure incidence. In particular, control over SCPS under transfer conditions covaries with a reduction in seizure frequency. Both results strengthen our hypotheses that surface-negative SCPs indicate cortical excitability, that the regulation of this excitability is impaired in epileptic patients, and that the control over one's own cortical excitability can be strengthened utilizing feedback and instrumental conditioning. It seems important to note that the ability to modulate excitability under transfer conditions, i.e., independently of immediate feedback. seems to exert a crucial influence on the change in seizure frequency.

However, not every patient seemed to be able to achieve this control, and not every patient who demonstrated reliable SCP control experienced a reduction in seizure frequency. We cannot expect that every'patient will learn to reliably control his: her SCPs and that every patient achieving SCP control will benerit from this ability. Only when the self-control is successfully transferred and applied in the everyday environment can it be effective. We should be abie to specify and quantify variabies determining such a success. Ultimately this task requires a very large patient sample but 
there are some tentative suggestions which can be derived from the present data and the case studies which we have presented previously ${ }^{20}$. First of all, age seems to be an important mediating variable: younger patients seem to learn and generalize SCP control better than the older ones; none of the patients over 35 was successful. A detrimental effect of age on the ability to achieve self-controt over brain activity has also been suggested by the observations of Sterman (personal communication). The age effect may be confounded with intellectual deterioration: Sterman reports age - IQ correlations with treatment success, and Daum et al. ${ }^{11}$ found correlations of verbal IQ with learning success in the present patient sample.

It might be expected that $A E D s$, many of which are central nervous depressants, might affect the brain's ability to learn and to adequately bring into action the learned regulation of $\mathrm{SCP} /$ cortical excitability. Apart from various impairing side effects of antiepileptic medication on learning and cognitive processing (as for example described by Penry and Rahel ${ }^{29}$ ), we ourselves have demonstrated dampening effects of two AEDs, carbamazepine (CBZ) and a benzodiazepine (clonazepam), on EEG and SCP generation in healthy human volunteers ${ }^{36.38}$. In the present study, two patients who became completely seizure-free following SCP training were not on current antiepileptic medication. On the other hand, some patients who did not show such substantial changes in seizure frequency were on heavy and long-term medication. However, medication was too heterogeneous in the present sample to allow an adequate analysis of its impact on learning and therapeutic outcome. More specific studies are certainly required in this respect.

It seems likely that the specific type of the epileptic disease, the locus of a focus or other characteristics of the disease might be relevant for the ability to achieve SCP control and its impact on seizure frequency. However, the present sample was too small and too homogeneous with respect to type of epilepsy (most patients suffering from complex focal seizures) to allow any conclusion about the mediating role of the type of epilepsy.

A crucial variable seems to be motivation. Observations in three patients of the present sample re- vealed that these patients can successfully control seizures if they concentrate on their ' $B$ ' strategy upon discrimination of prodromal signs. However, if they fail to concentrate on SCP control because something else attracts their attention they experience a seizure. In one case the patient even mentioned not utilizing the learned strategy while having a tight with her partner. Motivation should be monitored more carefully in quantitative terms in future studies to allow specification of the impact of this tentative intervening variable.

Another variable that has to be examined in future studies is training time. Twenty-eight training sessions within 2 months were chosen for the present study. For successful sensorimotor rhythm training 18 sessions $^{43}$ and training periods of 4 months ${ }^{25}$ have been reported. The time needed to learn a specific task varies a great deal from subject to subject, but unlike motor skill learning, the simple rule of the more extensive the training, the higher the skill seems not to apply for operant learning of EEG parameters. The present data suggest that learning occurs in steps rather than smoothly over time. As reported by Sterman ${ }^{43}$. benefits from sensorimotor rhythm training increased during the period following treatment. This, however, will interact with the motivation of the patient to practise his strategies of SCP control.

It is likely that other factors play important roles in determining the outcome of SCP feedback in epileptic patients. However, the strong evidence that epileptic patients can achieve control over their SCPs and the evidence that this control can affect seizure frequency at least in some patients encourages us to further explore feedback and instrumental conditioning of cortical excitability as an alternative and additional instrument in the treatment of epileptic patients.

\section{Acknowledgements}

The neurological advice of Dr. med. Ekhart Altenmüller and Dr. med. Erich Scholz is gratefully acknowledged. Research was supported by the Deutsche Forschungsgemeinschaft (SFB 307) and the Foundation Michael. 


\section{References}

I Birbaumer. N.. Elbert. T., Canavan, A. and Rockstroh, B., Slow potentials of the cerebral cortex and behavior, Physiol. Rev., 70 (1990) 1- +1 .

2 Birbaumer, N., Elbert, T., Rockstroh, B., Daum, I.. Wolf. P. and Canavan. A., Clinical-psychological treatment of epileptic seizures: A controlled study. In: A. Ehlers, I. Florin, W. Fiegenbaum and J. Margraf (Eds.), Perspectives and Promises of Clinical Psychology. Plenum Press. New York. NY, 199l, pp. $81-96$.

3 Braitenberg, V., Cell assemblies in the cerebral cortex. In: R Heim and G. Paim (Eds.), Theoretical Approach to Complex Systems, Springer, Berlin/Heidelberg, 1978, pp. 171-188.

4 Bühring, $M$. and Weltek, H., Entwickiung eines systematischen Anfallsunterbrechungstrainings, dargestellt anhand einer exemplarischen Fallstudie. In: P. Wolf (Ed.), Epilepsie 89, Einhorn. Reinbeck, 1990, pp. 216-220.

5 von Bülow. I.. Elbert. T., Rockstroh. B., Lutzenberger. W., Canavan, A and Birbaumer, N., Effects of hyperventilation on EEG frequency and slow cortical potentials in relation to an anticonvulsant and epilepsy, Psychophysiology, 3 (1989) $147-154$

6 Caspers, H. and Speckmann, E.J., DC-potential shifts in paroxysmal states. In: H.H. Jasper, A.A. Ward and A Pope (Eds.), Basic Mechanisms of the Epilepsies, Little Brown, Boston. MA, 1969.

7 Caspers, H.. Speckmann, E.J. and Lehmenkuehler, A., Electrogenesis of slow potentials of the brain. [n: T. Elbert, B. Rockstroh, W. Lutzenberger and N. Birbaumer (Eds.). SelfRegulation of the Brain and Behavior, Springer, Berlin/Heidelberg, 1984, pp. 25-4I.

8 Chatrian, G.E., Somasundaram, M. and Tassinari. C.A., DC-changes recorded transcranially during 'typical' $3 / \mathrm{sec}$ spike and wave discharges in men. Epilepsia, 9 (1968) 185209.

9 Dahl, J., Brorson, L.O. et al., Effects of a broad-spectrum behavior modification treatment program on children with refractory epileptic seizures. Epilepsia. 26 (1985) 303-309.

10 Dahl, J., Melin, L. and Leissner, P., Effects of a behavioral intervention on epileptic seizure behavior and paroxysmal activity: A systematic replication of three cases of children with intractable epilepsy, Epilepsia. 29 (1988) 172-193.

11 Daum, I., Rockstroh, B., Elbert, T., Birbaumer, N., Canavan, A.G.M. and Lutzenberger, W., Behavioral treatment of slow cortical potentials in intractable epilepsies: Neuropsvchological predictors of outcome, J. Neurol. Neurosurg. Psychiatry, (199?) in press.

12 Efron, R.. Conditioned inhibition of uncinate fits, Brain, 80 (1957) 251-260.

13 Elbert, T., Selbstregulation Langsamer Kortikaler Porentiale. Minerva. Munich. 1978

14 Elbert, T., Slow cortical potentials reflect the regulation of cortical excitability. In: W.C. McCallum and H. Curry Eds.). Slow Potentials in the Human Brain. Plenum Press. Yew York, NY, 1992 (in press)

15 Elbert, T., Birbaumer, N., Lutzenberger. W. and Rockstroh.
B., Biofeedback of slow cortical potentials: self-regulation of central autonomic patterns. In: N. Birbaumer and H.D Kimmei (Eds.), Biofeedback and Selfregulation. Lawrence Erlbaum Associates. Hillsdale, NJ. 1979. pp. 321-342.

16 Elbert. T., Rockstroh. B., Lutzenberger, W. and Birbaumer, N., Biofeedback of slow cortical porentials, J. Electroenceph. Clin. Neurophysiol., 48 (1980) 293-301.

17 Elbert, T., Rockstroh, B., Lutzen berger, W. and Birbaumer, N. (Eds.), Self-Regulation of the Brain and Behavior, Springer, Berlin/Heidelberg, 1984.

18 Elbert, T. and Rockstroh, B., Threshold regulation - a key to the understanding of the combined dynamics of EEG and event-related potentials, J. Psychophysiol., 1 (1987) 317-333.

19 Elbert. T., Birbaumer, N. and Rockstroh, B., Regulation of slow cortical potentials (SCP) in epileptic patients. In: C.H.M. Brunia, A.W.K. Gaillard and A. Kok (Eds.), Psv chophysiological Brain Research, University Press, Tilburg, 1990. pp. 231-235.

20 Elbert, T., Rockstroh, B., Canavan, A., Birbaumer, N.. Lutzenberger, W., von Bülow. I. and Linden, A., Seif-regulation of slow cortical potentials and its role in epileptogenesis. In: J. Carison and R. Seifert (Eds.), Biobehavioral Self-Regulation and Health, Plenum Press, New York, NY, 1991. pp. 65-94.

21 Forster, F.M., Conditioned reflexes and sensory-evoked epilepsy: The nature of the therapeutic process, Condit. Reflex, 4 (1969) 103-114.

22 Forster, F.M. The classification and conditioning treatment of the reflex epilepsies, Int. J. Neurol., 9 (1972) 73-86.

23 Forster. F.M.. Reflex Epilepsy, Behavioral Therapy, and Conditional Reflexes, Thomas, Springfield, IL, 1977.

24 Fried, R., Rubin, S.R., Carlton, R.M. and Fox, M.C., Behavioral control of intractable idiopathic seizures: I. Selfregulation of end-tidal carbon dioxide, Psychosom. Hed.. 46 (1984) 315-332.

25 Lubar, J., Application of operant conditioning of the EEG for the management of epileptic seizures. In: T. Elbert. B. Rockstroh. W. Lutzenberger and N. Birbaumer (Eds.). Self-Regulation of the Brain and Behavior, Springer, Berlin, Heidelberg, 1984, pp. 107-125.

26 Lutzenberger, W., Elbert. T., Rockstroh, B. and Birbaumer. N., Effects of slow cortical potentials on performance in a signal detection task, int. J. Neurosci., 9 (1979) 175-183.

27 McCallum. W.C.. Potentials related to expectancy. preparation and motor activity. In; T.W. Picton (Ed.), Fimman Event-Related Potentials, Elsevier, Amsterdam. 1988. pp. 427-534.

28 Mitzdorf. U... Current source density method and application in cat cerebral cortex: Investigation of evoked potentials and EEG phenomena, Phrsiol. Rev. 65 (1985) 37-99.

29 Penry. K. and Rahel, R.E.. Epilepsy: Diagnosis, Management. Quality of Life. Raven Press, New York. NY. 1986.

30 Roberts. L.. Rockstroh. B.. Lutzenberger. W., Elbert. I and Birbaumer. N.. Self-reports during feedback regularion of slow cortical potentiais, Psychophvsiology, 26 (1989) 392- 
403.

31 Rockstroh. B.. Hyperventilation-induced DC-potentials in human subjects, Epiiepsy Res., 7 (1990) 146-154.

32 Rockstroh. B.. Regulation of cortical excitability and SP regulation in patients with epilepsy and its measurement by means of slow cortical potentials. In: W.C. McCallum and H. Curry (Eds.), Slow Potentials in the Human Brain. Plenum Press. New York, NY. 1992, in press.

33 Rockstron. B. and Elbert, T., On the regulation of excitability in cerebral cortex - A bridge between EEG and attention?, In: H.G. Geissler, M. Müller and W. Prinz (Eds.), Psychophysical Explorarions of Mental Structures, Hogrefe. Göttingen, 1990. pp. 323-332.

34 Rockstroh. B.. Elbert. T., Lutzenberger. W. and Birbaumer, $N$., Operant control of slow brain potentials: A tool in the investigation of the potential's meaning and its relation to attentive dysfunction. In: T. Elbert, B. Rockstroh, W. Lutzenberger and N. Birbaumer (Eds.), Self-Regulation of the Brain and Behavior. Springer. Berlin/Heidelberg, 1984, pp. 277-239.

35 Rockstroh, B., Birbaumer. N., Elbert. T. and Lutzenberger, W., Operant control of EEG, event-related and slow poten-. tials. Biofeedback and Self-Regulation, 9 (1984) 139-160.

36 Rockstron. B., Elbert. T., Lutzenberger, W. Altenmüller, E.. Diener, H.C., Birbaumer, N. and Dichgans, J., Effects of the anticonvulsant carbamazepine on event-related brain potentials in humans. In: R. Nodar, C. Barber and T. Blum (Eds.), Evoked Potentials III, Butterworths, London, 1987 , pp. 361-369.

37 Rockstroh, B., Elbert, T., Canavan, A., Lutzenberger, W. and Birbaumer, N.. Slow Cortical Potentials and Behavior, 2nd Edn.. Urban \& Schwarzenberg, Munich. 1989.

38 Rockstroh, B.. Elbert. T., Lutzenberger, W. and Altenmüller. E., Effects of the anticonvulsant benzodiazepine clona- zepam on event-related potentials in human subjects, $f$ Electroenceph. Clin. .Veurophysiol.. 78 (1991) 142-149.

39 Sasaki, K. and Gemba. H.. Cortical potential associated with voluntary movements. In: C.H.M. Brunia, G. Mulder and M.V. Verbaten (Eds.), Psychophysiological Brain Research, University Press, Tilburg, 1991, pp. 80-96.

40 Speckmann, E.-J. and Elger, C.E., Neurophysiological basis of the EEG and of DC-potentials. In: E. Niedermeyer and F. Lopes da Silva (Eds.), Electroencephalography, Urban \& Schwarzenberg, Baltimore, MD, 1982, pp. 1-13.

41 Speckmann, E.-J., Caspers, H. and Elger, C.E., Neuronal mechanisms underlying the generation of lield potentials. In: T. Elbert. B. Rockstroh, W. Lutzenberger and N. Birbaumer (Eds.), Self-Regulation of the Brain and Benavior, Springer, Berlin/Heidelberg, 1984, pp. 9-25.

42 Sterman, M.B., Lantz. D., Bruckler, R.M. and Kovalesky, R.A., Effects of senscrimotor EEG normalization feedback training on seizure rate in poorly controlled epileptics. Proceedings of the Biofeedback Sociery of America, 12th Annual Meeting, Louisville, KY, 1981.

43 Sterman. M.B.. The role of sensorimotor rhythmic EEG activity in the etiology and treatment of generalized motor seizures. In: T. Elbert. B. Rockstroh. W. Lutzenberger and N. Birbaumer (Eds.), Self-Regulation of the Brain and Behavior, Springer, Berlin/Heidelberg, 1984, pp. 95-106

44 Stodieck. S.R. and Wieser, H.G., Epicortical DC-changes in epileptic patients. In: P. Wolf, M. Dam and E. Dreifuss (Eds.), Advances in Epileptology, Raven Press, New York, NY, 1987, pp. 123-128.

45 Wolf, P. and Dockweiler, U., Deconditioning therapy in a patient with versive seizures precipitated by touch. In: A. Beaumandir. H. Gastaut and M. Naguet (Eds.), Reflex Seizures and Reflex Epilepsies, Medicine et Hygiène, Geneva, 1989, pp. 447-451. 